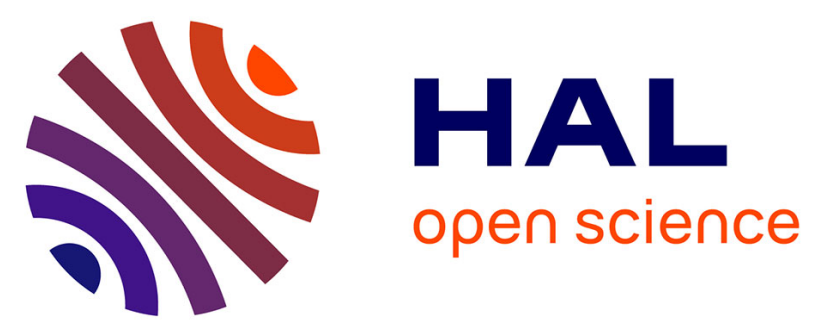

\title{
Identification of new natural sweet compounds in wine using centrifugal partition chromatography-gustatometry and fourier transform mass spectrometry
}

Axel Marchal, Pierre Waffo-Téguo, Eric Génin, Jean-Michel Merillon, Denis

Dubourdieu

\section{To cite this version:}

Axel Marchal, Pierre Waffo-Téguo, Eric Génin, Jean-Michel Merillon, Denis Dubourdieu. Identification of new natural sweet compounds in wine using centrifugal partition chromatography-gustatometry and fourier transform mass spectrometry. Analytical Chemistry, 2011, 83 (24), pp.9629 - 9637. 10.1021/ac202499a . hal-02645956

\section{HAL Id: hal-02645956 \\ https://hal.inrae.fr/hal-02645956}

Submitted on 29 May 2020

HAL is a multi-disciplinary open access archive for the deposit and dissemination of scientific research documents, whether they are published or not. The documents may come from teaching and research institutions in France or abroad, or from public or private research centers.
L'archive ouverte pluridisciplinaire HAL, est destinée au dépôt et à la diffusion de documents scientifiques de niveau recherche, publiés ou non, émanant des établissements d'enseignement et de recherche français ou étrangers, des laboratoires publics ou privés. 


\title{
Identification of New Natural Sweet Compounds in Wine Using Centrifugal Partition Chromatography-Gustatometry and Fourier Transform Mass Spectrometry
}

\author{
Axel Marchal, ${ }^{*,+,}$ Pierre Waffo-Téguo, ${ }^{\S}$ Eric Génin,, Jean-Michel Mérillon, ${ }^{\S}$ and Denis Dubourdieu ${ }^{+, \neq}$ \\ ${ }^{\dagger}$ Université de Bordeaux, ISVV, EA 4577, Unité de Recherche OENOLOGIE, F-33882 Villenave d'Ornon, France \\ ${ }^{\ddagger}$ INRA, ISVV, USC 1219 OENOLOGIE, 33882 Villenave d'Ornon, France \\ ${ }^{\S}$ Université de Bordeaux, ISVV, GESVAB, EA 3675, F-33882 Villenave d'Ornon, France \\ "Thermo Fisher Scientific, LC/MS Laboratory, 16 Avenue du Québec, F-91140 Villebon sur Yvette, France
}

Supporting Information

\begin{abstract}
Sweetness contributes notably to the taste-balance of dry wines and increases during oak-barrel aging owing to the release of natural sweeteners from wood. The search for such taste-active molecules, which are sometimes present at very low concentrations in wine or other complex matrixes, requires both reliable purification tools and powerful identification techniques. Here, we report the development of an original inductive method using centrifugal partition chromatography (CPC) and sensorial analysis. This method, called CPC-gustatometry, was implemented to isolate a sweet fraction with only four compounds from a complex oak wood extract. The recently developed Fourier transform mass spectro-

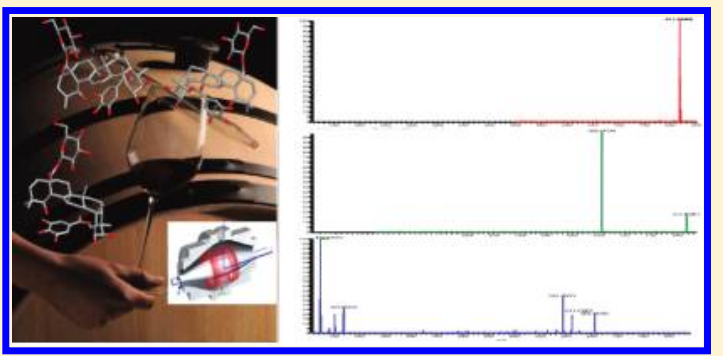
metry (FT-MS, Orbitrap analyzer) was used jointly with two-dimensional nuclear magnetic resonance $\left(2 \mathrm{D}{ }^{1} \mathrm{H}\right.$ and ${ }^{13} \mathrm{C}$ NMR) to obtain the structural elucidation of the purified compounds. The tandem mass spectrometry (MS/MS) spectra obtained with resonant and nonresonant fragmentation modes were compared, thus providing complementary information about the molecular structure. Two oleanane-type triterpenoids substituted with galloyl and glucosyl moieties were identified, one of which exhibits sweet properties. We term these compounds which have never been reported, Quercotriterpenoside I and II.
\end{abstract}

$\mathrm{W}$ ine quality, i.e., the pleasure that a wine brings to the taster, depends on the complexity and the harmony of its aromas and tastes. The mental representation of this quality in the taster's field of consciousness is based on the sensorial perception of the various wine chemicals followed by the neurophysiological and cognitive integration of the perceived stimuli. ${ }^{1}$

The sweet taste, conjuring up the taste of sucrose, paradoxically characterizes the gustatory balance of dry wines and particularly great wines. It softens the acidity, bitterness, and astringency generated by some wine molecules like organic acids and polyphenols. ${ }^{2}$ In such dry wines, grape carbohydrates (mainly glucose and fructose) are almost completely transformed by yeasts, so they are present only at very low concentrations and are not perceptible. The perceived sweetness corresponds therefore to "sweetness without sugar" and ensures the consumer's pleasure. However, despite evidence of their sensorial importance, the molecular determinants of sweetness in dry wines have never been elucidated.

Nevertheless, winemakers are convinced that aging in oak wood barrels has a sweetening effect on wine. ${ }^{3}$ A similar taste improvement contributes to maturation and the global quality of spirits.

In addition, it is well-known that molecules exhibiting sweet taste are naturally contained in plants, and some of them are now used as sweeteners in the food industry like steviosides. ${ }^{4-6}$
Consequently, nonvolatile compounds with sweet taste may be present in oak wood and then be released in wines and spirits during aging. The search for such compounds is comparable to the study of natural substances with biological and pharmacological properties, a pathway that has led to numerous analytical developments. ${ }^{7-10}$ This kind of research involves a dual requirement: purification (only traces of active molecules are present in a complex matrix) and identification (compounds are purified following their biological activity and not their chemical structure, which therefore requires elucidation). ${ }^{11,12}$ Consequently, it is necessary to use efficient analytical techniques to meet this dual challenge.

Among these techniques, centrifugal partition chromatography (CPC) is particularly suited for the fractionation of complex extracts, owing to the large amounts that can be injected and the lack of irreversible adsorption with the stationary phase. ${ }^{13-15}$ By implementing this technique, we have developed an original taste-guided purification protocol, i.e., fractionation steps of an oak extract have been hyphenated with tasting of the obtained fractions.

\section{Received: September 21, 2011}

Accepted: November 1, 2011

Published: November 01, 2011 
However, while the purification of compounds makes it possible to test their organoleptic properties, complementary analytical methods are necessary for structural determination. Fourier transform mass spectrometry has been the subject of promising recent developments (the Orbitrap analyzer). ${ }^{16,17}$ Its use in conjunction with multidimensional $\mathrm{NMR}^{18}$ provides valuable information with a view to determining the molecular structure of natural purified compounds.

The implementation of these different techniques allowed us to isolate and identify new oak wood compounds exhibiting a sweet taste. The methodology developed constitutes a novel and promising approach to study compounds responsible for wine flavor and other taste-active molecules, including novel sweeteners of plant origin.

\section{EXPERIMENTAL SECTION}

Taste-Guided Fractionation and Purification. CPC Apparatus. The fractionation was performed on an FCPC 200 Kromaton Technologies apparatus (Angers, France) fitted with a rotor made of 20 circular partition disks ( 1320 partition cells, $130 \mu \mathrm{L}$ per cell; column capacity of $204 \mathrm{~mL}$; dead volume, $32.3 \mathrm{~mL}$ ). The rotation speed can be adjusted from 0 to $2000 \mathrm{rpm}$. The solvents were pumped by a Gilson 321-H1 two-way binary high-pressure gradient pump. The samples were introduced into the CPC column via a high-pressure injection valve (3725(i)038 Rheodyne) equipped with a $10 \mathrm{~mL}$ sample loop. The effluent was monitored with a Varian UV Prostar 325 (Les Ulis, France) detector in dual mode equipped with a preparative flow cell. Fractions were collected by a Gilson FC 204 fraction collector. The experiments were conducted at room temperature.

Solvent System Screening. The choice of an appropriate biphasic system of solvents is based on the study of the partition of the compounds of the extract in both phases. In practice, $1 \mathrm{mg}$ of extract is dissolved in a biphasic system $(2 \mathrm{~mL})$ in a vial. After shaking, $100 \mu \mathrm{L}$ of each phase was evaporated to dryness, resolubilized with $1 \mathrm{~mL}$ of methanol/water $(1: 1 ; \mathrm{v} / \mathrm{v})$, and injected into an analytic HPLC. The partition coefficient $K_{\mathrm{d}}$ was calculated as the ratio of the solute area in each phase. The quaternary Arizona systems ( $n$-heptane/ethyl acetate/methanol/water) B, C, D, F, H, $\mathrm{J}, \mathrm{K}, \mathrm{L}$, and $\mathrm{M}$ were tested. ${ }^{19,20}$ In optimal conditions in ascending mode where $K_{\mathrm{d}} \approx 1$, the compounds are partitioned equally between the two phases and a satisfactory separation may occur. The Arizona-G system (1:4:1:4, v/v) was chosen on this basis.

Preparation of CPC Solvent. A biphasic system was prepared by mixing $n$-heptane $(200 \mathrm{~mL})$, ethyl acetate (EtOAc, $800 \mathrm{~mL})$, methanol $(\mathrm{MeOH}, 200 \mathrm{~mL})$, and $\mathrm{H}_{2} \mathrm{O}(800 \mathrm{~mL})$ in a separatory funnel at room temperature, shaking vigorously, and allowing them to settle until the phases became limpid. The resulting two phases were separated just before use.

Preparation of the Prepurified Extract. The oak heartwood used in this work came from staves of Quercus petraea trees grown in Caucasia and were seasoned outside, without shelter, for at least 24 months. A total of $500 \mathrm{~g}$ of wood chips $(30 \mathrm{~mm} \times 20 \mathrm{~mm} \times 5 \mathrm{~mm}$, Seguin-Moreau) were soaked in $2 \mathrm{~L}$ of hydro-alcoholic solution (50\% ethanol) at $20^{\circ} \mathrm{C}$ without stirring. After 20 days, the liquid medium was filtered $(0.45 \mu \mathrm{m})$ and concentrated in vacuo to remove ethanol. The aqueous extract was extracted three times with $200 \mathrm{~mL}$ of $n$-heptane. This aqueous layer was then extracted with EtOAc $(5 \times 250 \mathrm{~mL})$. The combined organic layers were evaporated in vacuo, suspended in water, and freeze-dried twice to give $802 \mathrm{mg}$ of prepurified extract (brown-orange powder).
CPC Separation Procedure. In CPC, either the lower phase or upper phase of the biphasic solvent system can be used as the mobile phase. In our experiment, the rotor was filled by injecting $500 \mathrm{~mL}$ of the aqueous heavier stationary phase in ascending mode at $10 \mathrm{~mL} / \mathrm{min}$ and at $300 \mathrm{rpm}$. Then the rotation speed was increased to $1200 \mathrm{rpm}$. The mobile phase was pumped into the column in ascending mode at $10 \mathrm{~mL} / \mathrm{min}$. When the thermodynamic equilibrium was reached (percentage of retention of the stationary phase, $72.5 \%$ ), the sample solution containing $700 \mathrm{mg}$ of dry prepurified extract dissolved in $6 \mathrm{~mL}$ of a mixture consisting of upper and lower phase $(4: 2, \mathrm{v} / \mathrm{v})$ was injected through a $10 \mathrm{~mL}$ loop. Acquisition began at the moment of injection, and UV detection was carried out at 254 and $280 \mathrm{~nm}$. The fraction collector was set at 1 tube/min. The system was switched to descending mode at tube 68 . The aqueous heavier phase was pumped at $10 \mathrm{~mL} / \mathrm{min}$. The whole experiment lasted $90 \mathrm{~min}$ and was performed at room temperature $\left(20^{\circ} \mathrm{C}\right)$.

Analytic HPLC $-U V$. After the CPC experiment, the tubes were analyzed by HPLC-UV. A volume of $100 \mu \mathrm{L}$ of liquid were taken from each tube, evaporated, and dissolved in water/ acetonitrile $50 / 50$. After filtration $(0.45 \mu \mathrm{m}), 10 \mu \mathrm{L}$ of the samples obtained were analyzed on an Ultrasphere ODS C18 $4.6 \mathrm{~mm} \times 250 \mathrm{~mm}, 5 \mu \mathrm{m}$ column (Beckman Coulter, Fullerton, CA) connected to a Spectra System autosampler, quaternary pump, and diode array detector (Thermo Fisher Scientific, Les Ulis, France). The mobile phases were water (A) and acetonitrile (B), each containing $0.1 \%$ trifluoroacetic acid. The gradient was 0 min, 10\% B; 2 min, 10\% B; 19 min, 70\% B; 20 min, 95\% B; $23 \mathrm{~min}, 95 \%$ B; $24 \mathrm{~min}, 10 \%$ B; $27 \mathrm{~min}, 10 \%$ B with a flow rate of $1 \mathrm{~mL} / \mathrm{min}$. Signal detection was carried out at $280 \mathrm{~nm}$.

Constitution of Fractions and Tasting. After HPLC analysis, $\mathrm{CPC}$ tubes presenting similar chromatographic profiles were combined, evaporated in vacuo, suspended in water, and freezedried twice. A total of 15 fractions numbered from I to XV were also obtained and contained various quantities (from 3 to 148 $\mathrm{mg}$ ) of powder (yellow to dark brown). In total, $3 \mathrm{mg}$ of each fraction were suspended in $600 \mu \mathrm{L}$ of ethanol and $60 \mathrm{~mL}$ of water. The samples were then tasted in normalized glasses by four experts in wine tasting. They described the gustatory perception for each fraction using the vocabulary of wine tasting and evaluated in particular the sweetness intensity (from 0 to 5 ).

HPLC Purification. Purification was performed on a C18 preparative column (Microsorb 100-5 $250 \mathrm{~mm} \times 21.4 \mathrm{~mm}, 5 \mu \mathrm{m}$ particle size, Varian) connected to a precolumn (Prontosil C18 $5 \mu \mathrm{m} 50 \mathrm{~mm} \times 20 \mathrm{~mm}$, Bischoff chromatography). Solvents (water (A) and acetonitrile (B), both containing $0.05 \%$ trifluororacetic acid) were pumped by a Prostar 218 two-way binary highpressure gradient pump (Varian). The flow rate was $20 \mathrm{~mL} / \mathrm{min}$ and eluant B followed this gradient: $0 \mathrm{~min}, 8 \%$; $5 \mathrm{~min}, 18 \% ; 13$ min, 18\%; 26 min, 26\%; $35 \mathrm{~min}, 36 \%$; $50 \mathrm{~min}, 50 \%, 52 \mathrm{~min}$, $100 \%$; $57 \mathrm{~min}, 100 \%$. Initially, $17 \mathrm{mg}$ of fraction $\mathrm{X}$ were dissolved in methanol $(200 \mu \mathrm{L})$, filtered $(0.45 \mu \mathrm{m})$, and manually introduced into the system. UV detection was carried out at 254 and $280 \mathrm{~nm}$ by a Prostar 345 detector (Varian). Chromatographic peaks were manually collected, just after the detector. Purification of the entire fraction X (52 mg) was completed by a total of three successive injections. The four samples obtained (corresponding to the four peaks of fraction $\mathrm{X}$ ) were evaporated in vacuo to remove acetonitrile and freeze-dried twice to give four white powders. These compounds were added in water and dry white wine $(10 \mathrm{mg} / \mathrm{L}, 100 \mathrm{~mL})$ and then tasted by five experts in wine-tasting. 
Table 1. Gustatogram of the AcOEt Prepurified Extract of Oak Wood

\begin{tabular}{|c|c|c|c|}
\hline fraction & tubes & sensory description & obtained mass (mg) \\
\hline I & $8-13$ & bitter in attack, dry, "dust flavor" & 148 \\
\hline II & 14 and 15 & "coconut flavor", intense and lingering bitterness & 63 \\
\hline III & $16-19$ & slightly sweet (intensity 2), then mushy in final & 53 \\
\hline IV & 20 & slight bitterness & 17 \\
\hline $\mathrm{V}$ & $21-24$ & slightly sweet in attack (intensity 1 ), astringent and bitter & 43 \\
\hline $\mathrm{VI}$ & $25-31$ & sweetness in attack (intensity 2); very intense and lingering bitterness, astringency & 57 \\
\hline VII & $32-36$ & not very sapid, bitter in finish & 44 \\
\hline VIII & $37-39$ & intense astringency, bitter finish & 15 \\
\hline IX & $40-47$ & slight astringency, moderate sweetness (intensity 2 ) & 28 \\
\hline $\mathrm{X}$ & $48-63$ & very sapid, intense and lingering sweetness (intensity 4) & 59 \\
\hline XI & $64-68$ & bitterness, slight sweetness (intensity 2 ) & 11 \\
\hline XII & $69-73$ & intense sweetness perceived in attack (intensity 3), lingering on the tip of the tongue & 27 \\
\hline XIII & $74-78$ & tingly numbness, sweetness in finish (intensity 2), slight bitterness & 57 \\
\hline XIV & $79-81$ & sweetness (intensity 3 ) & 7 \\
\hline $\mathrm{XV}$ & $82-90$ & no taste & 3 \\
\hline
\end{tabular}

FTMS. Direct infusion measurements were performed on an LTQ Orbitrap Velos (Thermo Fisher Scientific, Bremen, Germany) mass spectrometer equipped with a heated ESI ion source. The sample was dissolved to $10 \mathrm{ng} / \mu \mathrm{L}$ in $\mathrm{CH}_{3} \mathrm{OH} / \mathrm{H}_{2} \mathrm{O}$ $1: 1(\mathrm{v} / \mathrm{v})$ and delivered by a syringe pump with a flow rate of $5 \mu \mathrm{L} / \mathrm{min}$. External calibration of the mass spectrometer was performed using a mixture consisting of caffeine, MRFA peptide, and Ultramark 1621 polymer. The ion source was operated in the negative ion mode at $4 \mathrm{kV}$. The vaporizer temperature of the source was set at $150{ }^{\circ} \mathrm{C}$, the capillary temperature at $280^{\circ} \mathrm{C}$, the nitrogen sheath gas at 40, and the auxiliary and sweep gas at 0 (arbitrary units). The ion lenses were automatically optimized using the $10 \mathrm{ng} / \mu \mathrm{L}$ solution of purified compounds. A mass range of 200-1000 Th was acquired in full scan MS mode.

Collision induced dissociation (CID) $\mathrm{MS}^{2}$ and $\mathrm{MS}^{3}$ studies were performed in the linear ion trap (LIT). In addition, nonresonant activation was also carried out in the higher collisional energy (HCD) cell situated at the far end of the C-Trap region. ${ }^{21}$ In both cases, the product ions were detected in the Orbitrap analyzer in order to generate high mass accuracy data. Indeed, all the ions were detected with mass errors in the 1 ppm range. ${ }^{22}$ The resolution setting was $100000(\mathrm{~m} / \Delta \mathrm{m}$, fwhm at $m / z 400)$ in the MS and $\mathrm{MS}^{n}$ modes. The maximum injection time was set at $100 \mathrm{~ms}$ and the automated gain control (AGC) target value, respectively, at $5 \times 10^{5}$ in MS and $5 \times 10^{4}$ in $\mathrm{MS}^{n}$. An isolation width of 1 Th was used both for the CID MS ${ }^{n}$ and the HCD MS/MS experiments.

NMR Experiments. The experiments were performed on a Bruker Avance 3 spectrometer $\left({ }^{1} \mathrm{H} 600 \mathrm{MHz},{ }^{13} \mathrm{C} 150 \mathrm{MHz}\right)$ equipped with a TXI $5 \mathrm{~mm}$ probe and a Bruker Avance DMX 500 spectrometer $\left({ }^{1} \mathrm{H} 500 \mathrm{MHz},{ }^{13} \mathrm{C} 125 \mathrm{MHz}\right)$ equipped with a TXI $5 \mathrm{~mm}$ cryo-probe. All NMR spectra were acquired at $27^{\circ} \mathrm{C}$ in methanol- $d_{4}$. 1D ${ }^{1} \mathrm{H}$ NMR spectra were recorded with $32 \mathrm{k}$ data points, sweep width of $12 \mathrm{ppm}$, and pulse repetition time of $1.5 \mathrm{~s}$. Correlation spectroscopy (COSY), rotating frame nuclear Overhauser effect spectroscopy (ROESY) (400 ms spin lock), and heteronuclear single-quantum correlation spectroscopy (HSQC)/ total correlation spectroscopy (TOCSY) (150 ms spin lock) spectra were performed with 2048-256 data points. HSQC and heteronuclear multiple-bond correlation spectroscopy (HMBC) spectra were acquired using gradient selection. The heteronuclear correlations were optimized for ${ }^{1} J_{\mathrm{C}, \mathrm{H}} 140 \mathrm{~Hz}$ and ${ }^{n} J_{\mathrm{C}, \mathrm{H}} 8-12 \mathrm{~Hz}$ depending on the sample. Spectral widths were adjusted to the individual samples. ${ }^{1} \mathrm{H}$ and ${ }^{13} \mathrm{C}$ chemical shifts were referenced to solvent signals of methanol- $d_{4}, \delta\left({ }^{1} \mathrm{H}\right) 3.31$ and $\delta\left({ }^{13} \mathrm{C}\right) 49.1$.

\section{RESULTS AND DISCUSSION}

Use of CPC Off-Line Hyphenated with Gustatometry to Isolate and Purify Sapid Compounds. CPC Fractionation of Prepurified Extract. The hydro-ethanolic extract of staves of Quercus petraea trees grown in Caucasia was partitioned successively using solvents with increasing polarity: n-heptane and EtOAc. The EtOAc prepurified extract was subjected to CPC using Arizona-G system $n$-heptane/EtOAc/ $\mathrm{MeOH} / \mathrm{H}_{2} \mathrm{O}$ (1:4:1:4, $\mathrm{v} / \mathrm{v})$ to provide 90 tubes.

The CPC-UV profile (Figure S-1 in the Supporting Information) showed some distinct broad peaks distributed across the chromatogram, confirming the good partitioning of the extract. In order to locate the sapid compounds of the extract, the CPC tubes had to be tasted. Since there were many tubes (90), fractions were constituted by grouping some tubes together. Grouping was done on the basis of the analytical HPLC chromatographic profiles. The HPLC chromatograms obtained from the different tubes presented many peaks but were quite different, confirming the fractioning efficiency of the CPC. When grouping the tubes, samples presenting the same main peaks and similar HPLC chromatographic profiles were pooled together. The 15 (I to XV) fractions thus constituted provided $632 \mathrm{mg}$ of powder after freeze-drying. In comparison to other chromatographic techniques, the yield of this CPC experiment (90\%) was very high. This was mainly due to the principle of CPC, which involves no solid support, i.e., no irreversible adsorption. Moreover, CPC offers the possibility of injecting large quantities of extract. Consequently, this technique appears very powerful for the search for nonvolatile compounds with organoleptic properties in complex matrixes.

To locate the targeted compounds, all the fractions were tasted and their sweetness intensity was evaluated. Even if the number of tasters (four) was low owing to the small quantity of product available, their expertise in wine-tasting ensured the pertinence of their judgment. 


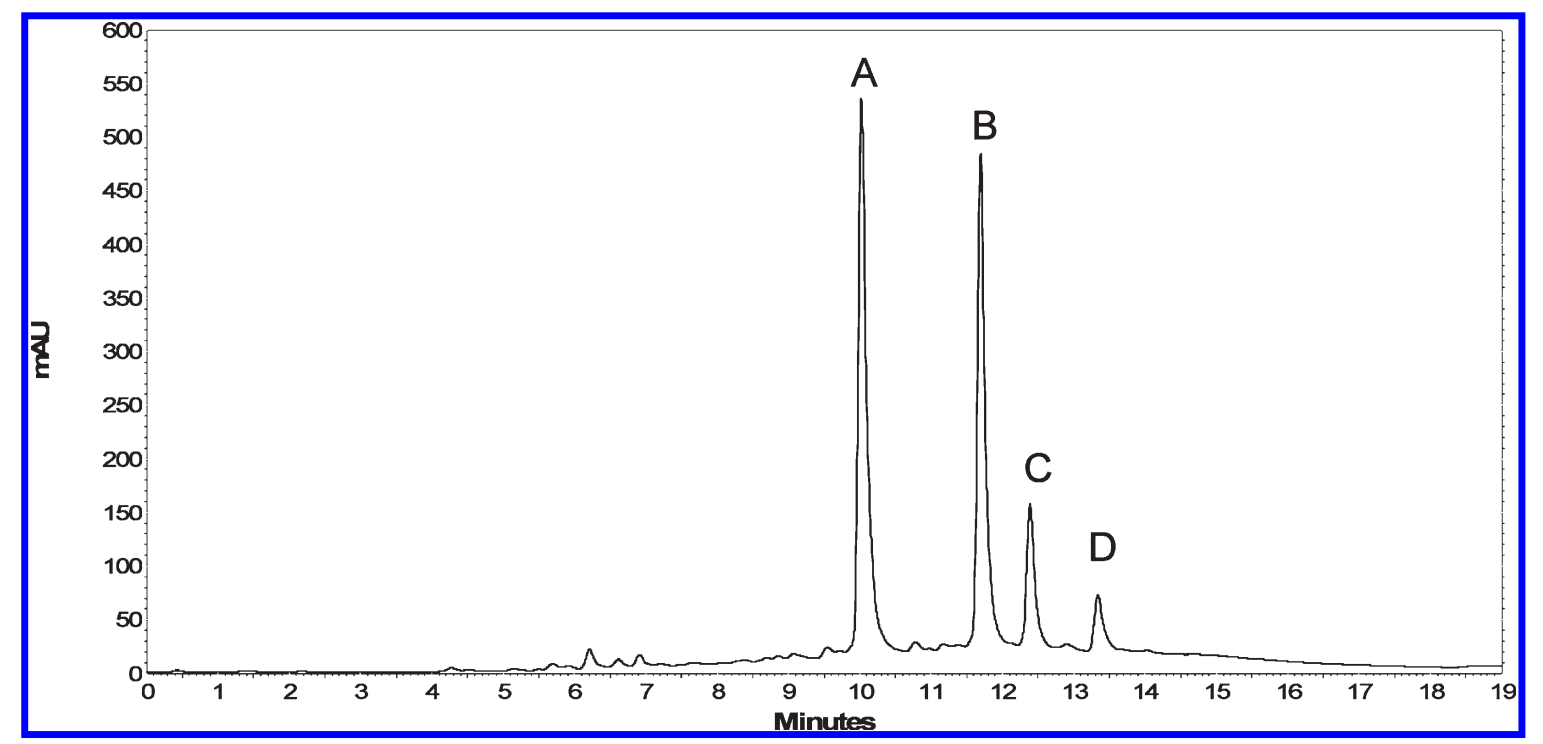

Figure 1. HPLC-UV chromatogram of fraction X: UV chromatogram at $280 \mathrm{~nm}$ of fraction X shows four well-separated and symmetric peaks corresponding to four compounds labeled $\mathbf{A}-\mathbf{D}$.

To study volatile compounds, aromaticians have for long hyphenated gas chromatography with olfaction (GC-O) and used the terms "olfactometry" and "olfactogram". 23,24 By analogy, we chose to call our technique "gustatometry". Centrifugal partition chromatography followed by gustatometry allowed the tasters to establish a gustatogram of the extract (Table 1). They used precise sensorial descriptors corresponding to fundamental taste (sweetness, bitterness), tactile sensations (astringency), and multimodal perceptions ("dusty flavor", "coconut flavor"). For most fractions, the taste was composed of multiple sensations, indicating their chemical heterogeneity as revealed by HPLC profiles.

As shown in Table 1, eight fractions developed a characteristic sweet taste with different intensities. The most intense sweetness was perceptible in fraction X (yellow powder, $59 \mathrm{mg}$ ). Its HPLC chromatogram (Figure 1) showed only four main peaks, corresponding probably to four compounds (A, B, C, and D, in increasing order of retention time).

A fraction containing only four compounds and exhibiting a sweet taste was also obtained from a highly complex extract. This new hyphenation technique termed CPC-G therefore appears powerful for the study of nonvolatile compounds with gustative properties. Because of the need for evaporation of organic solvents prior to sensorial analysis, this hyphenation technique is not online, contrary to GC-O.

Purification and Sensorial Characterization of Fraction $X$ Compounds. Fraction X (52 mg) was submitted to preparative HPLC using a water/acetonitrile gradient. The four peaks were well separated and the compounds were obtained as white powders after freeze-drying (A, $16 \mathrm{mg} ; \mathrm{B}, 4.9 \mathrm{mg} ; \mathrm{C}, 1.2 \mathrm{mg}$; D, $0.3 \mathrm{mg}$ ). The general yield of this purification step (44\%) was lower than for the CPC experiment but was commonly obtained with HPLC. Irreversible adsorption due to the solid phase in the $\mathrm{C} 18$ column and the manual collection method could explain this difference. This demonstrates the value of CPC vis-a-vis HPLC for extract fractionation, although the higher chromatographic resolution obtained in HPLC remains useful for final compound purification.

The same procedure was repeated three times and the purified compounds A, B, and $\mathbf{C}$ were then tasted at $10 \mathrm{mg} / \mathrm{L}$ in water and in dry white wine by five expert tasters. Despite the general sweetness of fraction $\mathbf{X}$, its main constituent, compound $\mathbf{A}$, was perceived as bitter by the tasters both in water and wine. Compound B was tasteless in water and did not modify the taste of wine. On the other hand, compound $\mathbf{C}$ exhibited a sweet taste in water, significantly enhanced the sweetness of wine, and reduced its bitterness. Therefore, this compound likely contributes substantially to the sweetness perceived in fraction $\mathbf{X}$. Compound $\mathbf{D}$ was not tasted owing to the small quantity available $(0.9 \mathrm{mg})$ and the destructive nature of gustative analysis. HPLC purification and sensorial characterization established the sweet properties of compound $\mathbf{C}$, in particular when added in wine.

Molecular Identification of the Isolated Compounds Using FTMS and NMR. Sensory analysis allowed us to determine the taste of each compound purified from fraction $\mathbf{X}$ and showed in particular that compound $\mathbf{C}$ exhibits a sweet taste. In order to identify the structure of the isolated compounds, two powerful techniques were used: Fourier transform mass spectrometry (FTMS) and nuclear magnetic resonance (NMR). For this study, we used the example of the sweet compound $\mathbf{C}$ to illustrate the complementarity of these analytic techniques for identifying unknown natural molecules. The main results for the three others compounds are briefly presented.

Empirical Formula Determination Using FTMS. The mass accuracy, stability, and resolution afforded by FTMS are particularly useful for the empirical determination of the formulas of unknown natural molecules. The full scan spectrum of compound $\mathbf{C}$ (Figure 2) exhibits an $[\mathrm{M}-\mathrm{H}]^{-}$ion at $m / z 817.40082$ as the base peak. To calculate the corresponding formula, only elements $\mathrm{C}, \mathrm{H}$, and $\mathrm{O}$ were considered with the following constraints: $0<\mathrm{C}<50,0<\mathrm{H}<100$, and $0<\mathrm{O}<30$. For this quasimolecular $[\mathrm{M}-\mathrm{H}]^{-}$ion, the neutral formula of $\mathrm{C}_{43} \mathrm{H}_{61} \mathrm{O}_{15}$ was calculated as the first hit with a mass accuracy better than $1 \mathrm{ppm}$. The second hit was $\mathrm{C}_{50} \mathrm{H}_{57} \mathrm{O}_{10}$ with a mass error of $6.2 \mathrm{ppm}$ far beyond the $3 \mathrm{ppm}$ specifications of our LTQ-Orbitrap instrument. Moreover, the number of carbon atoms did not reflect the relative experimental isotopic abundance of $45 \% .{ }^{25}$ Additional formulas with very small mass errors were obtained by adding further elements $(\mathrm{N}, \mathrm{P}, \mathrm{S})$ in the constraints, but none of them 


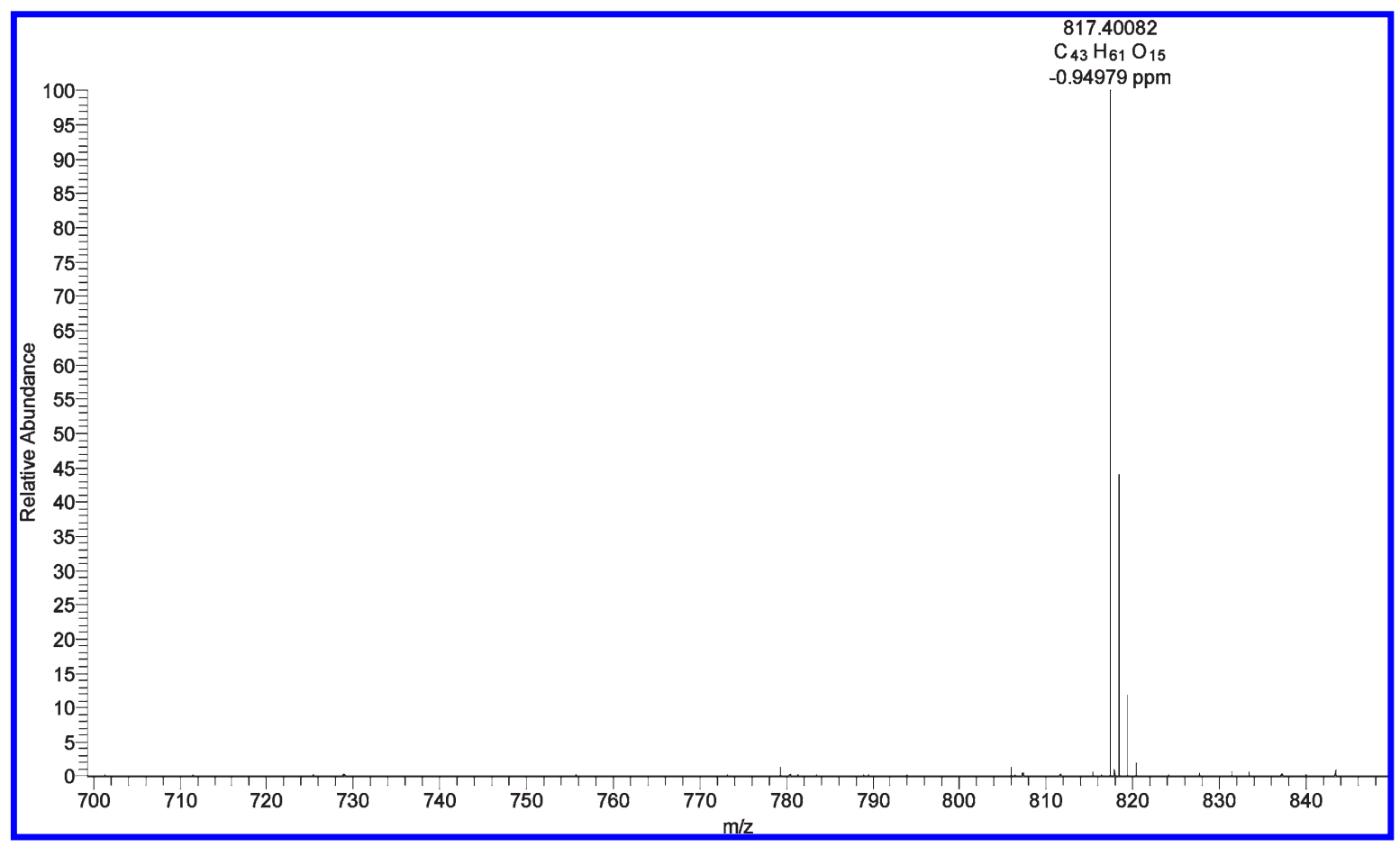

Figure 2. Orbitrap negative ion full scan MS of Quercotriterpenoside I (compound C): The spectrum exhibits the quasi-molecular ion at $m / z$ $817.40082 \mathrm{Th}$, with an isotopic ratio of $45 \%$, corresponding to the empirical formula $\mathrm{C}_{43} \mathrm{H}_{61} \mathrm{O}_{15}$.

was compatible with the accurate mass $\mathrm{MS}^{n}$ data shown below. Consequently, the empirical formula $\mathrm{C}_{43} \mathrm{H}_{62} \mathrm{O}_{15}$ was assigned to compound $\mathbf{C}$. Using the same method, the formulas of compounds $\mathbf{A}$ and $\mathbf{B}$ were determined as $\mathrm{C}_{22} \mathrm{H}_{28} \mathrm{O}_{8}$ and $\mathrm{C}_{22} \mathrm{H}_{32} \mathrm{O}_{12}$, respectively. Moreover, compound $\mathbf{D}$ was an isomer of compound $\mathrm{C}\left(\mathrm{C}_{43} \mathrm{H}_{62} \mathrm{O}_{15}\right)$.

Structural Identification Based on NMR Data. To identify the structure of compound C, extensive NMR techniques $1 \mathrm{D}\left({ }^{1} \mathrm{H},{ }^{13} \mathrm{C}\right)$ and 2D (COSY, ROESY, TOCSY-HSQC, HSQC, and HMBC) were used.

Among the 43 carbons, 30 were assigned to a triterpenoid aglycone, 6 to a sugar moiety and the remaining 7 to a galloyl group. Six signals of the triterpenoid moiety were assigned to methyl carbons at $\delta 12.3,15.7,16.3,23.4,23.5$, and 27.4 and the corresponding protons were identified by an HSQC experiment (Table 2). Three oxygen-bearing methine carbons were found at $\delta 67.9,76.4$, and 80.9 , a hydroxymethyl carbon was detected at $\delta$ 65.2, and a pair of olefenic carbons was observed at $\delta 123.1$ and 143.5. When coupled with information from the ${ }^{1} \mathrm{H}$ NMR spectrum, i.e., six methyl singlets at $\delta 0.76,0.86,0.95,0.96$, 1.08 and 1.19 , three oxygen-bearing methine protons at $\delta 3.27$ $(d, J=4.0), 3.45(d, J=9.9), 3.76(t d, J=9.9,4.3)$, a primary alcohol function at $\delta 4.07(d, J=11.3 \mathrm{~Hz})$ and $4.23(d, J=11.3 \mathrm{~Hz})$, and an olefinic proton at $\delta 5.33(t, J=3.3 \mathrm{~Hz})$, this data was characteristic of a polyhydroxyolean-12-ene triterpene derivative. After observation of the connectivities in COSY, HSQC, HSQCTOCSY, and HMBC experiments, the triterpene skeleton of C was identified as arjungenin (olean-12-ene- $2 \alpha, 3 \beta, 19 \alpha, 23 \alpha$ tetrol) ${ }^{26}$ The stereochemistry was verified by a ROESY experiment. Moreover, the presence of one singlet of two protons at $\delta$ $7.10\left(\mathrm{H}-2^{\prime \prime}, \mathrm{H}-6^{\prime \prime}\right)$ on the ${ }^{1} \mathrm{H}$ NMR spectrum, and carbon atoms of one carbonyl at $\delta 166.9\left(\mathrm{C}-7^{\prime \prime}\right)$, one aromatic quaternary carbon at $\delta 120.2\left(\mathrm{H}-1^{\prime \prime}\right)$, two aromatic methines at $\delta 108.2$ $\left(\mathrm{C}-2^{\prime \prime}, \mathrm{C}-6^{\prime \prime}\right)$, and three quaternary oxygenated carbons at $\delta 138.7\left(\mathrm{C}-4^{\prime \prime}\right)$ and $145.2\left(\mathrm{C}-3^{\prime \prime}, \mathrm{C}-5^{\prime \prime}\right)$ on the ${ }^{13} \mathrm{C}$ NMR spectrum evidenced the presence of the galloyl group in compound $\mathrm{C}$. The downfield chemical shift of $\mathrm{H}-23$ ( $\delta 4.07$ and 4.23) of $\mathrm{C}$ and its correlation with C-7" $(\delta 166.9)$ of galloyl in the HMBC experiment established that galloyl esterified C-23 of the aglycone. The aglycone of compound $\mathbf{C}$ was thus 23 - $O$-galloylarjungenin. Furthermore, the presence of an anomeric proton signal at $\delta 5.38(d, J=8.6 \mathrm{~Hz})$, in addition to several signals between $\delta 3.31$ and 3.82 on the ${ }^{1} \mathrm{H}$ NMR spectrum and the six signals of carbon atoms on the ${ }^{13} \mathrm{C}$ NMR spectrum at $\delta 94.5$ (C$\left.1^{\prime}\right), 72.6\left(\mathrm{C}-2^{\prime}\right), 77.2\left(\mathrm{C}-3^{\prime}\right), 69.7\left(\mathrm{C}-4^{\prime}\right), 76.9\left(\mathrm{C}-5^{\prime}\right)$, and 61.1 $\left(\mathrm{C}-6^{\prime}\right)$, confirmed the presence of a terminal glucose unit. The relative stereochemistry of this sugar moiety was determined as $\beta$-glucopyranose on the basis of the characteristic $J_{1,2}$ coupling constant of its anomeric proton $(J=8.2 \mathrm{~Hz})$ and typical ${ }^{1} \mathrm{H}$ and ${ }^{13} \mathrm{C}$ NMR shifts. ${ }^{27}$ The linkage position of this glucose moiety at C-28 was evidenced by the upfield shift of this carbon from $\delta$ 180.1 to $\delta 176.7$ in compound $\mathrm{C}$ and the signal of the anomeric carbon $\left(\mathrm{C}^{\prime} 1^{\prime}\right)$ at $\delta$ 94.3. In addition, the HMBC cross peak correlation observed between the anomeric proton $\left(\mathrm{H}-\mathrm{l}^{\prime}\right)$ and C-28 confirmed the sugar linkage position at C-28. Thus, the structure of compound $\mathrm{C}$ was concluded to be a new triterpenoid, 23-O-galloyl arjungenin 28-O- $\beta$-glucopyranosyl (23-O-galloyl arjunglucoside). Owing to its botanical origin and its chemical nature, we called it Quercotriterpenoside I (QTT I, Figure 3).

FTMS of compound D gave a quasi-molecular peak at $\mathrm{m} / \mathrm{z}$ $[\mathrm{M}-\mathrm{H}]^{-} 817.40210$ in negative mode, in agreement with the molecular formula of $\mathrm{C}_{43} \mathrm{H}_{61} \mathrm{O}_{15} .{ }^{1} \mathrm{H}$ and ${ }^{13} \mathrm{C}$ NMR data (Table 2) of $\mathbf{D}$ were closely comparable to those of QTT I, except for signals of ring A. This suggested that compound $\mathbf{D}$ is a regioisomer of QTT I where the galloyl unit is transferred from C-23 to C-3. The position of the galloyl unit was confirmed by HMBC NMR, which showed a three-bond correlation between 
Table 2. ${ }^{1} \mathrm{H}$ and ${ }^{13} \mathrm{C}$ NMR Data of Quercotriterpenoside I and II

\begin{tabular}{|c|c|c|c|c|c|c|}
\hline & \multicolumn{3}{|c|}{ QTT I } & \multicolumn{3}{|c|}{ QTT II } \\
\hline & assignment & ${ }^{13} \mathrm{C}^{a}$ & ${ }^{1} \mathrm{H}^{b}$ & assignment & ${ }^{13} \mathrm{C}^{c}$ & ${ }^{1} \mathrm{H}^{d}$ \\
\hline & 1 & 46.4 & $0.99 m$ & 1 & 47.9 & $1.08 \mathrm{~m}$ \\
\hline & & & $1.98 d d(12.3 ; 4.3)$ & & & $2.05 \mathrm{~m}$ \\
\hline & 2 & 67.9 & $3.76 d(9.9 ; 4.3)$ & 2 & 65.7 & $3.94 \mathrm{td}(11 ; 4.6 \mathrm{~Hz})$ \\
\hline & 3 & 76.4 & $3.45 d(9.9)$ & 3 & 84.8 & $4.7 d(10.3 \mathrm{~Hz})$ \\
\hline & 4 & 42.4 & & 4 & 44.3 & \\
\hline & 5 & 47.8 & $1.38 \mathrm{~m}$ & 5 & 56.1 & $1.09 \mathrm{~m}$ \\
\hline & 6 & 17.8 & $1.48 \mathrm{~m}$ & 6 & 19.8 & $1.49 \mathrm{td}(13.3 ; 5.3 \mathrm{~Hz})$ \\
\hline & & & $1.39 \mathrm{~m}$ & & & $1.72 \mathrm{~m}$ \\
\hline & 7 & 31.9 & $1.26 \mathrm{~m}$ & 7 & 32.8 & $1.30 \mathrm{~m}$ \\
\hline & & & $1.42 \mathrm{~m}$ & & & $1.46 \mathrm{~m}$ \\
\hline & 8 & 39.4 & & 8 & 40.3 & \\
\hline & 9 & 48 & $1.85 t(9.3)$ & 9 & 47.9 & $1.87 t(9.0 \mathrm{~Hz})$ \\
\hline & 10 & 37.7 & & 10 & 38.1 & \\
\hline & 11 & 23.6 & $2.02 \mathrm{~m}$ & 11 & 23.7 & $2.05 \mathrm{~m}$ \\
\hline & 12 & 123.1 & $5.33 t(3.3)$ & 12 & 123 & $5.36 t(3.4 \mathrm{~Hz})$ \\
\hline & 13 & 143.5 & & 13 & 143.2 & \\
\hline & 14 & 41.2 & & 14 & 44.9 & \\
\hline & 15 & 27.8 & $0.95 \mathrm{~m}$ & 15 & 27.8 & $1.69 \mathrm{~m}$ \\
\hline & & & $1.62 \mathrm{~m}$ & & & $1.79 \mathrm{~m}$ \\
\hline & 16 & 26.9 & $1.7 \mathrm{~m}$ & 16 & 26.4 & $1.76 \mathrm{~m}$ \\
\hline & & & $2.3 \operatorname{td}(13.7 ; 4.3)$ & & & $2.35 \mathrm{td}(13.4 ; 3.6 \mathrm{~Hz})$ \\
\hline & 17 & 45.6 & & 17 & 45.3 & \\
\hline & 18 & 43.7 & $3.05 d(4.0)$ & 18 & 43.9 & $3.08 d(3.5 \mathrm{~Hz})$ \\
\hline & 19 & 80.9 & $3.27 d(4.0)$ & 19 & 81 & $3.30 \mathrm{~d}(3.5 \mathrm{~Hz})$ \\
\hline & 20 & 34.4 & & 20 & 34.3 & \\
\hline & 21 & 28 & $1.01 \mathrm{~m}$ & 21 & 28 & $1.02 \mathrm{~m}$ \\
\hline & & & $1.76 \mathrm{~m}$ & & & $1.70 \mathrm{~m}$ \\
\hline & 22 & 31.7 & $1.66 \mathrm{~m}$ & 22 & 32.1 & $1.66 \mathrm{~m}$ \\
\hline & & & $1.76 \mathrm{~m}$ & & & $1.76 \mathrm{~m}$ \\
\hline & 23 & 65.2 & $4.07 d(11.3)$ & 23 & 21.8 & $1.06 \mathrm{~s}$ \\
\hline & & & $4.23 d(11.3)$ & 24 & 63.9 & $3.85 d(11.6 \mathrm{~Hz})$ \\
\hline & 24 & 12.3 & $0.86 s$ & & & $3.90 \mathrm{~d}(11.6 \mathrm{~Hz})$ \\
\hline & 25 & 15.7 & $1.08 \mathrm{~s}$ & 25 & 15.7 & $1.15 s$ \\
\hline & 26 & 16.3 & $0.76 s$ & 26 & 16.5 & $0.79 s$ \\
\hline & 27 & 23.4 & $1.19 s$ & 27 & 23.8 & $1.33 \mathrm{~s}$ \\
\hline & 28 & 176.7 & & 28 & 177.5 & \\
\hline & 29 & 27.4 & $0.95 s$ & 29 & 27.2 & $0.97 s$ \\
\hline & 30 & 23.5 & $0.96 s$ & 30 & 23.8 & $0.96 s$ \\
\hline & $1^{\prime}$ & 94.5 & $5.38 d(8.2 \mathrm{~Hz})$ & $1^{\prime}$ & 94.4 & $5.39 d(8.2 \mathrm{~Hz})$ \\
\hline & $2^{\prime}$ & 72.6 & $3.31 d(9.1 \mathrm{~Hz})$ & $2^{\prime}$ & 72.3 & $3.32 \mathrm{~m}$ \\
\hline & $3^{\prime}$ & 77.2 & $3.35 \mathrm{~m}$ & $3^{\prime}$ & 77.3 & $3.35 \mathrm{~m}$ \\
\hline glucopyranosyl & $4^{\prime}$ & 69.7 & $3.36 d(8.1 \mathrm{~Hz})$ & $4^{\prime}$ & 69.6 & $3.37 \mathrm{~m}$ \\
\hline & $5^{\prime}$ & 76.9 & $3.44 d(9.1 \mathrm{~Hz})$ & $5^{\prime}$ & 77.1 & $3.41 d(9.2 \mathrm{~Hz})$ \\
\hline & $6^{\prime}$ & 61.1 & $3.69 d d(11.7 ; 4.1 \mathrm{~Hz})$ & $6^{\prime}$ & 61 & $3.69 d d(12.1 ; 4.4 \mathrm{~Hz})$ \\
\hline & & & $3.82 \operatorname{brd}(11.7 \mathrm{~Hz})$ & & & $3.83 \mathrm{brd}(11.1 \mathrm{~Hz})$ \\
\hline & $1^{\prime \prime}$ & & 120.2 & $1^{\prime \prime}$ & 120.3 & \\
\hline & $2^{\prime \prime} / 6^{\prime \prime}$ & $7.1 s$ & 108.2 & $2^{\prime \prime} / 6^{\prime \prime}$ & 108.3 & $7.13 s$ \\
\hline galloyl & $3^{\prime \prime} / 5^{\prime \prime}$ & & 145.2 & $3^{\prime \prime} / 5^{\prime \prime}$ & 144.9 & \\
\hline & $4^{\prime \prime}$ & & 138.7 & $4^{\prime \prime}$ & 138.2 & \\
\hline & $7^{\prime \prime}$ & & 166.8 & $7^{\prime \prime}$ & 167.1 & \\
\hline
\end{tabular}

${ }^{a}$ Chemical shift (in ppm) in $\mathrm{CD}_{3} \mathrm{OD}$ at $125 \mathrm{~Hz} \cdot{ }^{b}$ Chemical shift (in ppm); multiplicity, $\left(J\right.$, in $\mathrm{Hz}$ ) in $\mathrm{CD}_{3} \mathrm{OD}$ at $500 \mathrm{~Hz} .{ }^{c} \mathrm{Chemical}$ shift (in ppm) in $\mathrm{CD}_{3} \mathrm{OD}$ at $150 \mathrm{~Hz} .{ }^{d}$ Chemical shift (in ppm); multiplicity, $\left(J\right.$, in $\mathrm{Hz}$ ) in $\mathrm{CD}_{3} \mathrm{OD}$ at $600 \mathrm{~Hz}$. 


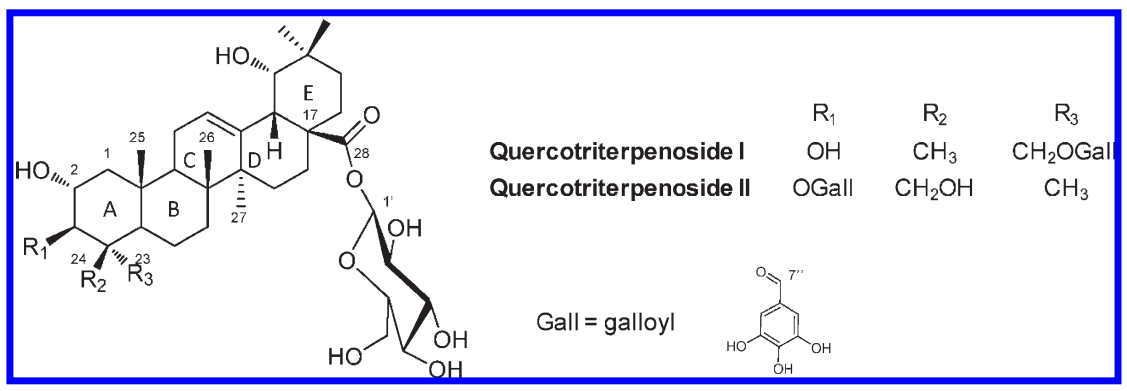

Figure 3. Molecular structure of Quercotriterpenoside I and II.

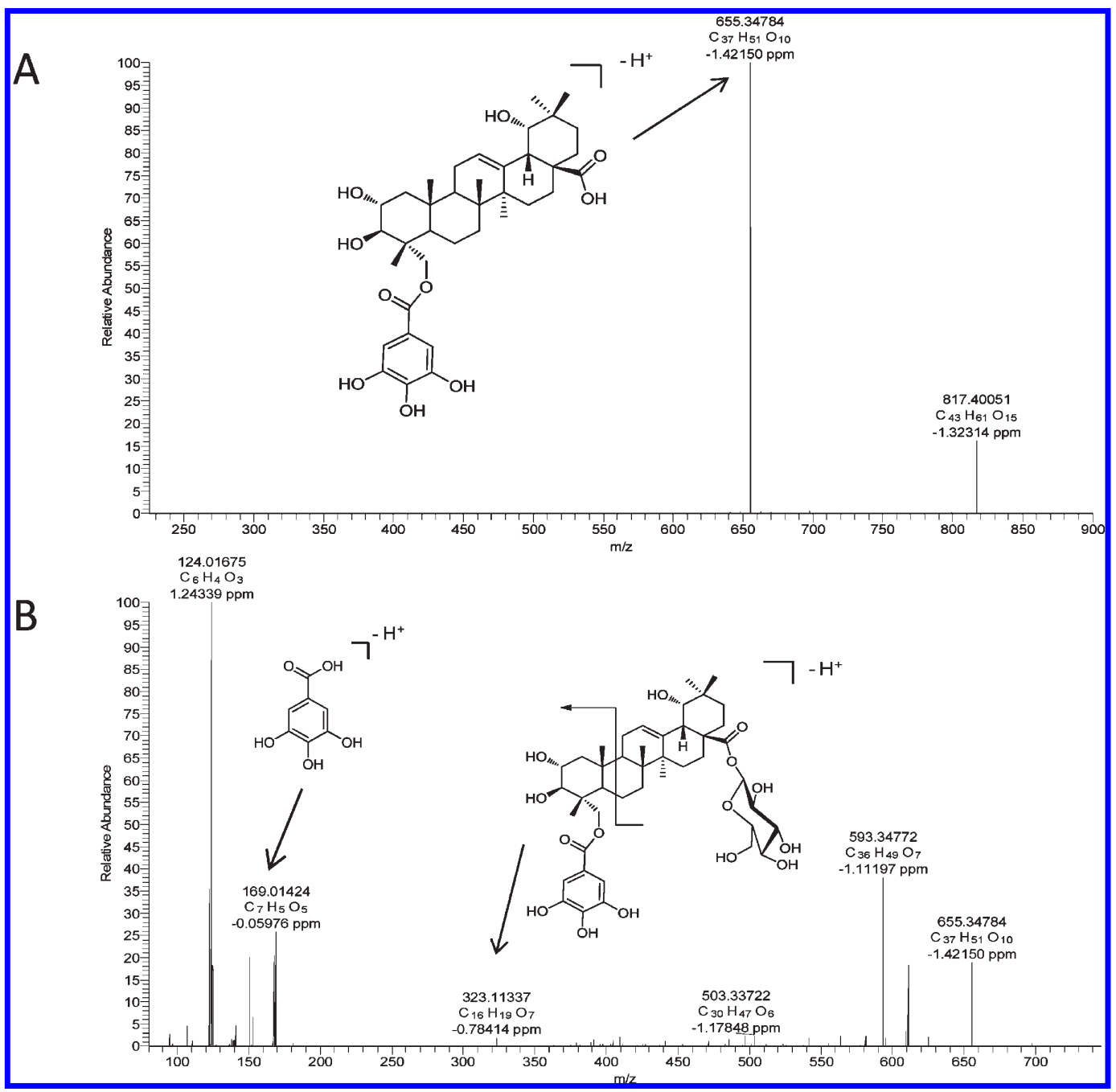

Figure 4. MS/MS spectra of the $[\mathrm{M}-\mathrm{H}]^{-}$ion of Quercotriterpenoside I: (A) LIT CID MS/MS at 22\% resonant collision energy, (B) HCD MS/MS at $150 \mathrm{~V}$ collision energy. The fragment at $\mathrm{m} / z 655.34784$ corresponds to the loss of glucosyl moiety. More ions were observed in HCD mode (B), in particular ions at $\mathrm{m} / z 323.11337$ and $\mathrm{m} / z 169.01424$ corresponding, respectively, to a fragment of QTT I (opening of ring B) and to the gallate ion.

the $\mathrm{H}-3$ signal at $\delta 4.7(1 \mathrm{H}, \mathrm{d}, J=10.3 \mathrm{~Hz})$ and $\mathrm{C}-7^{\prime \prime}$ at $\delta 167.1$ of the galloyl moiety. Moreover, the downfield chemical shift of protons $\mathrm{H}-24$ at $\delta 3.85(d, J=11.6 \mathrm{~Hz})$ and $3.90(d, J=$ $11.6 \mathrm{~Hz}$ ) according to the primary alcohol and the rOe interactions observed in the ROESY spectrum between $\mathrm{H}-3$ and $\mathrm{H}-23$ suggested that the stereochemistry of C-4 of genin had changed. The structure of $\mathbf{D}$ was concluded to be 3-O-galloyl 4-epi-arjunglucoside. This triterpenoid derived from sericoside (4-epi-arjunglucoside) was recently reported as a natural product from the bark of Terminalia ivorensis. ${ }^{28}$ This compound has never been described in the literature previously, so we named it Quercotriterpenoside II (QTT II, Figure 3).

Additionally, two known compounds, lyoniresinol (A) and whisky lactone precursor (B), were isolated and identified by comparing the observed ${ }^{1} \mathrm{H}$ and ${ }^{13} \mathrm{C}$ NMR data with the literature values. ${ }^{29-32}$ 


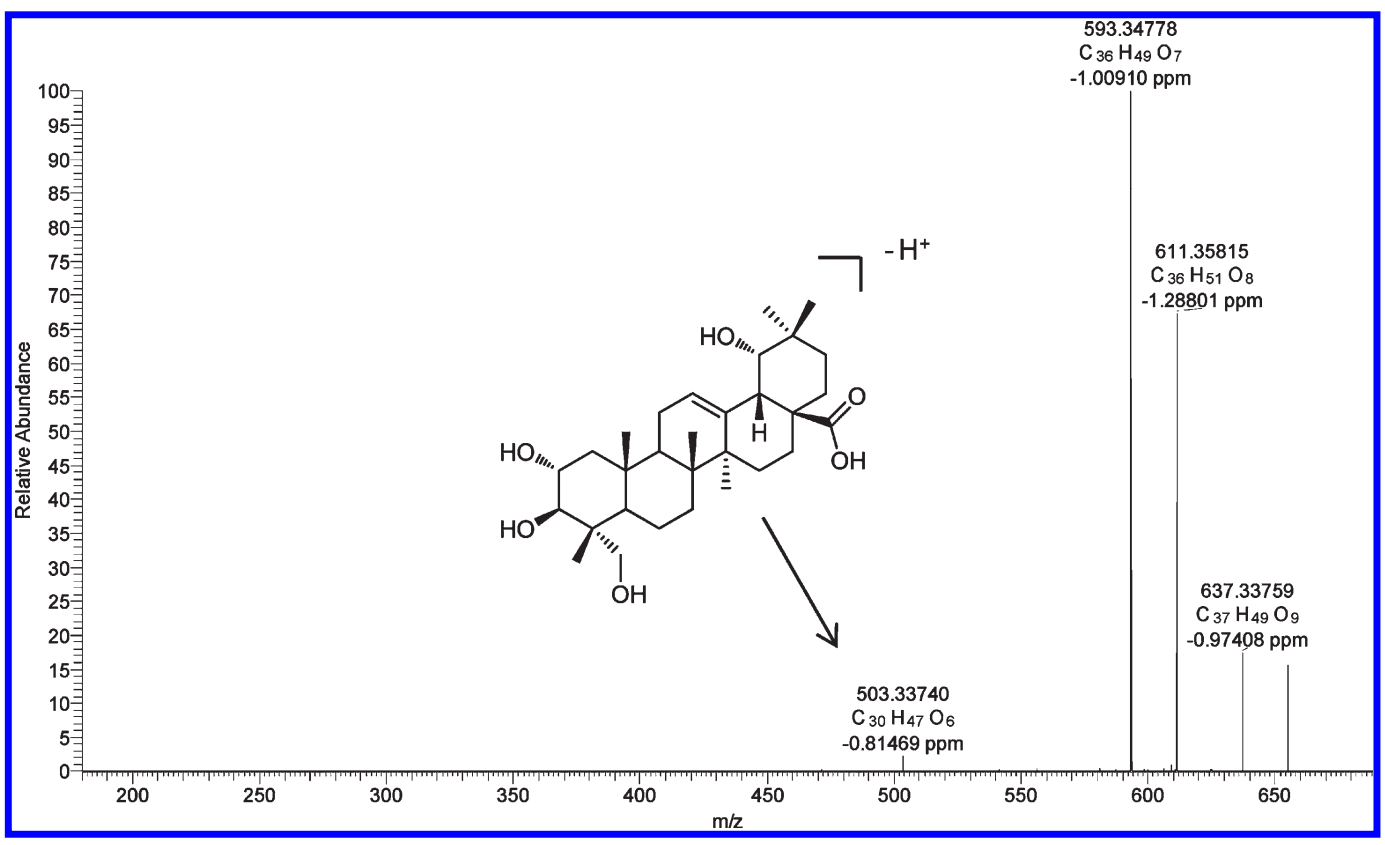

Figure 5. LIT MS 3 spectrum of the product ion at $m / z 655,30 \%$ resonant collision energy. The fragment at $m / z 503.33740$ corresponds to the genin ion of QTT I after the loss of galloyl and glucopyranosyl moieties, confirming the triterpenoide nature of the molecule.

Value of Coupling FTMS ${ }^{n}$ with CID and HCD Activations for Structural Confirmation. Fragmentation experiments in FTMS can provide valuable information to confirm the molecular structure proposed by NMR data interpretation, as illustrated with QTT I (C).

The resonant CID MS/MS spectrum of the precursor ion at $\mathrm{m} / \mathrm{z} 817$ (Figure 4) yielded one major fragment at $\mathrm{m} / \mathrm{z}$ 655.34784 which was attributed to the facile loss of a glucopyanosyl part ${ }^{33}$ and confirmed the presence of such a functional group. No other fragment was observed.

The next stage in the fragmentation process was the loss of water and carbon dioxide, as shown in the $\mathrm{MS}^{3}$ spectrum in Figure 5. The small product ion at $m / z 503.3374\left(\mathrm{C}_{30} \mathrm{H}_{47} \mathrm{O}_{6}\right)$ was attributed to the loss of a galloyl moiety, thus corresponding to the free triterpenoid ion.

A well-known drawback of the ion trap resonant activation process is the low mass cut off, which prevents product ions from being trapped below one-third of the precursor $m / z$ value. Even though this one-third ratio can be increased by decreasing the activation Qz parameter of the Matthieu equation, no fragments were observed on the $\mathrm{MS}^{3}$ spectrum below $180 \mathrm{Th}$.

The nonresonant HCD activation process is not subject to such a low mass cut off limitation. ${ }^{34}$ As shown in Figure 4 several intense product ions were observed at $m / z 169.01424\left(\mathrm{C}_{7} \mathrm{H}_{5} \mathrm{O}_{5}\right)$, $151.00377\left(\mathrm{C}_{7} \mathrm{H}_{3} \mathrm{O}_{4}\right), 125.0245\left(\mathrm{C}_{6} \mathrm{H}_{5} \mathrm{O}_{3}\right)$, and 124.01675 $\left(\mathrm{C}_{6} \mathrm{H}_{4} \mathrm{O}_{3}\right)$, thus providing further evidence of the presence of the galloyl moiety.

Unfortunately, no fragmentation of the triterpenoid ion was observed, with the exception of the small product ion at $\mathrm{m} / z$ $323.11337\left(\mathrm{C}_{16} \mathrm{H}_{19} \mathrm{O}_{7}\right)$, which could be formed by fragmentation at the B-ring. This fragment confirmed the position of the galloyl moiety on the A-ring of the aglycon. The HCD activation process provided precious structural information and therefore appears to be an interesting fragmentation mode, in addition to the widely used CID. FTMS ${ }^{n}$ results were complementary to the NMR data and confirmed the structure of QTT I.

\section{CONCLUSIONS}

The novel methodology consisting of an off-line centrifugal partition chromatography with gustatometry (CPC-G) hyphenation technique enabled the isolation of sapid compounds from an oak extract and, specifically, a sweet molecule. The power of this technique is based on the fractionation power of CPC with large amounts of extract and the accuracy of subsequent sensorial analysis. Furthermore, FTMS appears to be a powerful tool for structural studies, not only in full scan mode for determining the empirical formulas but also for determining the molecular structure of compounds in conjunction with ${ }^{1} \mathrm{H} /{ }^{13} \mathrm{C} 2 \mathrm{D}$ NMR. In this regard, CID and HCD fragmentation experiments provide relevant information that justifies their combination.

In this way, a new sweet triterpenoid called Quercotriterpenoside I was identified from an oak extract. These results illustrate the efficiency of the novel method, which allows the purification of taste-active molecules from highly complex mixtures. It could consequently be applied for the discovery of new natural sweeteners in various matrixes.

\section{ASSOCIATED CONTENT}

Supporting Information. CPC-UV chromatogram at $280 \mathrm{~nm}$ of the prepurified oak extract (Figure S-1). This material is available free of charge via the Internet at http://pubs.acs.org.

\section{AUTHOR INFORMATION}

\section{Corresponding Author}

*Phone: +33-557575867. Fax: +33-557575813. E-mail: axel. marchal@normalesup.org.

\section{ACKNOWLEDGMENT}

The authors would like to acknowledge the Conseil Interprofessionnel des Vins de Bordeaux, Laffort Oenologie, Seguin-Moreau 
cooperage and Rémy-Martin for funding this project. The authors thank Valérie Lavigne-Cruège and Alexandre Pons for sensorial analysis and Jonathan Bisson for the program cpc_plotter.

\section{REFERENCES}

(1) Brochet, F.; Dubourdieu, D. Brain Lang. 2001, 77, 187-196.

(2) Hufnagel, J. C.; Hofmann, T. L. Agric. Food Chem. 2008, 56, 1376-1386.

(3) Ribéreau-Gayon, P., Glories, Y., Maujean, A., Dubourdieu, D. Handbook of Enology, Vol. 2, The Chemistry of Wine Stabilization and Treatments; Jon Wiley \& Sons: Chichester, U.K., 2006.

(4) Tahara, A.; Nakata, T.; Ohtsuka, Y. Nature 1971, 233, 619-620.

(5) Geuns, J. M. C. Phvtochemistry 2003, 64, 913-921.

(6) Kim, N. C.; Kinghorn, A. D. Arch. Pharm. Res. 2002, 25, 725-746.

(7) Buszewski, B.; Kowalska, S.; Krupczyńska, K. Crit. Rev. Anal. Chem. 2005, 35, 89-116.

(8) Simoneit, B. R. T. Mass Spectrom. Rev. 2005, 24, 719-765.

(9) Kingston, D. G. I. I. Nat. Prod. 2011, 74, 496-511.

(10) Wolfender, J. L.; Ndjoko, K.; Hostettmann, K. J. Chromatogr., A 2003, 1000, 437-455.

(11) Robards, K. I. Chromatogr., A 2003, 1000, 657-691.

(12) Shi, S. Y.; Zhang, Y. P.; Jiang, X. Y.; Chen, X. Q.; Huang, K. L.; Zhou, H. H. TrAC, Trends Anal. Chem. 2009, 28, 865-877.

(13) Foucault, A. P. Anal. Chem. 1991, 63, 569A-579A.

(14) Lu, Y.; Berthod, A.; Hu, R.; Ma, W.; Pan, Y. Anal. Chem. 2009, 81, 4048-4059.

(15) Berthod, A.; Ruiz-Ángel, M. J.; Carda-Broch, S. J. Chromatogr., A 2009, 1216, 4206-4217.

(16) Hu, Q.; Noll, R. J.; Li, H.; Makarov, A.; Hardman, M.; Cooks, R. G. I. Mass Spectrom. 2005, 40, 430-443.

(17) Makarov, A. Anal. Chem. 2000, 72, 1156-1162.

(18) Reynolds, W. F.; Enríquez, R. G. I. Nat. Prod. 2002, 65, 221-244.

(19) Margraff, R. In Centrifugal Partition Chromatography; Foucault, A. P., Ed.; Chromatographic Science Series, Vol. 68; Marcel Dekker: New York, 1994; pp 331-350.

(20) Foucault, A. P.; Chevolot, L. I. Chromatogr., A 1998, 808, 3-22.

(21) Olsen, J. V.; Macek, B.; Lange, O.; Makarov, A.; Horning, S.; Mann, M. Nat. Methods 2007, 4, 709-712.

(22) Xu, Y.; Heilier, J. F.; Madalinski, G.; Genin, E.; Ezan, E.; Tabet, J. C.; Junot, C. Anal. Chem. 2010, 82, 5490-5501.

(23) Acree, T. E.; Butts, R. M.; Nelson, R. R.; Lee, C. Y. Anal. Chem. 1976, 48, 1821-1822.

(24) Delahunty, C. M.; Eyres, G.; Dufour, J. P. J. Sep. Sci. 2006, 29, 2107-2125.

(25) Koch, B. P.; Dittmar, T.; Witt, M.; Kattner, G. Anal. Chem. 2007, 79, 1758-1763.

(26) Jossang, A.; Seuleiman, M.; Maidou, E.; Bodo, B. Phytochemistry 1996, 41, 591-594.

(27) Agrawal, P. K.; Jain, D. C. Prog. Nucl. Magn. Reson. Spectrosc. 1992, 24, 1-90.

(28) Ponou, B. K.; Teponno, R. B.; Ricciutelli, M.; Quassinti, L.; Bramucci, M.; Lupidi, G.; Barboni, L.; Tapondjou, L. A. Phytochemistry 2010, 71, 2108-2115.

(29) Masson, E.; Baumes, R.; Le Guernevé, C.; Puech, J. L. J. Agric. Food Chem. 2000, 48, 4306-4309.

(30) Tanaka, T.; Kouno, I. I. Nat. Prod. 1996, 59, 997-999.

(31) Nabeta, K.; Yonekubo, J.; Miyake, M. Mokuzai Gakkaishi 1987, 33, 408-415.

(32) Rahman, M. D.; Katayama, T.; Suzuki, T.; Nakagawa, T. J. Wood Sci. 2007, 53, 161-167.

(33) Zehl, M.; Pittenauer, E.; Jirovetz, L.; Bandhari, P.; Singh, B.; Kaul, V. K.; Rizzi, A.; Allmaier, G. Anal. Chem. 2007, 79, 8214-8221.

(34) van der Heeft, E.; Bolck, Y. J. C.; Beumer, B.; Nijrolder, A. W. J. M.; Stolker, A. A. M.; Nielen, M. W. F. J. Am. Soc. Mass Spectrom. 2009, 20, 451-463. 